\title{
Are parents talking to adolescents about sexuality? Evidence from four slums in Ghana
}

\author{
Selina F. Esantsi \\ Population Council \\ Francis Onyango \\ Population Council \\ Gloria Quansah Asare \\ Emmanuel Kuffour \\ Population Council \\ Placide Tapsoba \\ Population Council
}

See next page for additional authors

Follow this and additional works at: https://knowledgecommons.popcouncil.org/departments_sbsr-rh

Part of the Demography, Population, and Ecology Commons, Family, Life Course, and Society Commons, Gender and Sexuality Commons, Inequality and Stratification Commons, International Public Health Commons, Maternal and Child Health Commons, and the Women's Health Commons How does access to this work benefit you? Let us know!

\section{Recommended Citation}

Esantsi, Selina F., Francis Onyango, Gloria Quansah Asare, Emmanuel Kuffour, Placide Tapsoba, Harriet Birungi, and lan Askew. 2015. "Are parents talking to adolescents about sexuality? Evidence from four slums in Ghana," STEP UP Evidence Brief. Nairobi: Population Council. 


\section{Authors}

Selina F. Esantsi, Francis Onyango, Gloria Quansah Asare, Emmanuel Kuffour, Placide Tapsoba, Harriet Birungi, and lan Askew 

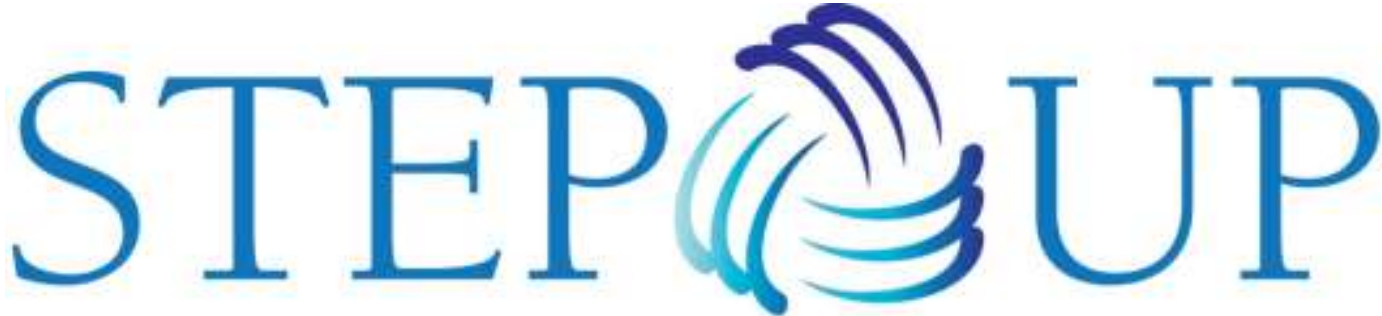

STRENGTHENING EVIDENCE FOR PROGRAMMING ON UNINTENDED PREGNANCY

August 2015

\section{Are parents talking to adolescents about sexuality? Evidence from four slums in Ghana}

STEP UP generates policy-relevant research to promote an evidencebased approach for improving access to family planning and safe abortion.

We work in Bangladesh, northern India, Ghana, Kenya, and Senegal.

Population Council Coordinating Partner

African Population and Health Research Center

icddr,b

London School of Hygiene and Tropical Medicine

Marie Stopes International

Partners in Population and Development

Funded by

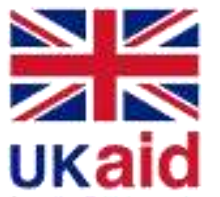

\section{INTRODUCTION}

The role of parents in their children's sex education is receiving increased public attention. Evidence suggests that parental attitudes play a large role in adolescent sexual behavior, and that frequent, open and positive sexuality communication between adolescents, parents, teachers and peers decreases risky sexual behavior and promotes positive behavior - including delaying sexual activity and promoting contraceptive use. (Bastien et al 2011) (Blake et al 2001). Rising rates of teenage pregnancy and HIV in Ghana are testament to this inadequately seized opportunity to help its young people.

Adolescent childbearing often has negative consequences, but without adequate educational support from parents, teens are less equipped to prevent pregnancy, avoid STIs and HIV, or negotiate safe sex. What is more, births to teenage girls have the highest infant and child mortality rates in Ghana.

Early childbearing may also foreclose a teenager's ability to pursue better educational or job opportunities. This is problematic because so many Ghanaian teenagers do become pregnant; the percentage of girls who have begun childbearing increases from less than $1 \%$ among 15 yearolds, to 29 percent among 19 year-olds (GDHS 2008).

Parents avoid discussing sexuality with their children because they may feel inhibited by cultural or personal taboos ((Botchway 2004) or lack accurate information themselves (Anggleton 2006). Some parents even believe discussing sexual matters with adolescents can promote early sexual intercourse (Botchway 2004). These attitudes can prompt an "abstinence-only" approach -- yet this can obstruct communication between children and parents and impede opportunities to provide the sexual education that has been demonstrated to reduce risky behavior.

This Evidence Brief summarizes the essential information from a part of a larger study that assessed the sexual and reproductive health $(\mathrm{SRH})$ needs of adolescents in four slums in two regions of Ghana. The objective of this brief is to provide evidence to support and facilitate the improvement of parent-adolescent communication on sexuality.

\section{KEY POINTS}

- Three out of five parents (61\%) had ever discussed sexual matters with their adolescents. However, of this figure, $66 \%$ indicated that they needed more information on family planning, contraception, STIs and HIVIAIDS to enable them have more meaningful discussions.

- Findings of this study are consistent with other studies that show the importance of parent-adolescent communication and of providing parents with information on adolescent sexual health

- Adolescents in this study rely heavily on teachers for sexual information. This finding is particularly significant since a national debate is ongoing over the best approach to sex education in schools.

- Adolescents - primarily girls - also tend to rely more on their mothers than their fathers for sexual information. On the topic of puberty, $35 \%$ of girls and $18 \%$ of boys would prefer to obtain information from their mothers, and on reproduction, $29 \%$ of girls and $14 \%$ of males would prefer this.

- The findings indicate that there is considerable potential for programs that encourage and train parents especially fathers - to impart sexual information to their children. The findings also emphasize the importance of supporting schoolbased sexuality education. 


\section{METHODOLOGY}

Data are from a cross-sectional study that employed quantitative methods to assess adolescent SRH knowledge and perceptions of adolescents and their parents or guardians. Data was collected using a semi-structured questionnaire. The sample size was determined using Cochran's sample size formula. Data was collected in March 2013 in four urban slums in Ghana: two (2) in the Greater Accra Region (Nima and Ashiaman) and two (2) (Sunyani East and Atebubu) in the Brong Ahafo Region.

\section{Study subjects}

- A total of 1303 adolescents aged 13-19 years were recruited for the study.

- A total of 626 parents/guardians were interviewed.

\section{KEY FINDINGS}

\section{Characteristics of respondents}

Adolescents

- More than half $(58 \%)$ of the adolescent respondents were female.

- Adolescents aged 18-19 years comprised the highest proportion (40\%) of the sample ( $42 \%$ males and $38 \%$ females).

- Nearly all (96\%) of the adolescents had ever attended school. Slightly over half of the adolescents $(57 \%)$ had completed primary education. Among respondents who had ever attended school, $75 \%$ were still in school ( $78 \%$ of males and $74 \%$ of females).

- Fifty five percent $(55 \%)$ of adolescents were Christian, and $43 \%$ were Muslim.

- Nearly all adolescents interviewed (97\%) had at least one living parent. Among those with at least one living parent, $70 \%$ reported that a parent was living with them in the same household.

\section{Guardians}

- Four in five guardians were females.

- Sixty-six per cent $(66 \%)$ of guardians interviewed were the biological parents of the adolescents.

- Other guardians included grandparents $(10 \%)$ and uncles and aunties (15\%).

- Slightly over half (57\%) of the parent/guardians had one adolescent between ages 13 and 19 years, and about a third (31\%) had two.
In order to have meaningful discussions with

their adolescents, caregivers themselves

need to have accurate information.

$66 \%$ of caregivers needed more information

on family planning, contraceptive use, STIS

and HIV/AIDS. 5\% needed information on

abortion, $8 \%$ on puberty, rape and peer

pressure, and $9 \%$ on marriage.

\section{Parental knowledge of adolescent SRH services}

The vast majority ( $95 \%$ ) of guardians did not know of any health facilities or NGOs which provide SRH services to adolescents. However, nine out of ten $(91 \%)$ would permit their adolescents to receive both information and services from them. Similarly, 91\% would allow their wards to seek services from health facilities although only $20 \%$ knew of any facilities. A high proportion (97\%) of guardians wanted SRH information to be provided in schools. Less than $10 \%$ of them disapproved of the provision of SRH services to adolescents.

\section{Parental rules on what to read or watch}

Watching television can be an important part of family interaction. It is also a source of information on sexuality that can either be productive or destructive for adolescents.

When asked about whether they set rules over what their adolescents watch or read, over half $(57 \%)$ of the parents/guardians reported that they did. Of those, $31 \%$ prohibited adult films and movies with sex scenes; $31 \%$ permitted only educational programs; $11 \%$ prohibited non-educational magazines; and one per cent permitted only religious programs. Twenty three percent (23\%) established other kinds of rules with a reward-basis for television and reading permission, such as for performing household chores, studying every evening, and observing personal hygiene.

\section{How do adolescents prefer to receive SRH information?}

About $79 \%$ of males and $64 \%$ of females indicated that they currently receive information on puberty from their school teachers. Seventy four percent $(74 \%)$ of males and $65 \%$ of females receive information on pregnancy and sexual and reproductive from school as well. This indicates that the school system does provide adolescents with significant information on sexual maturation and related issues. 
However, many adolescents (a higher proportion of females than males) would prefer to obtain information on puberty from their mothers (35\% and $18 \%$ respectively). In a similar trend (as can be seen on Table 1), a substantial proportion would prefer to receive the information on reproduction from their mothers ( $29 \%$ of females and $14 \%$ of males).

Interestingly, almost half of the adolescents ( $45 \%$ of females and $49 \%$ of males) obtained information on relationships principally from their friends, but only $22 \%$ of females and $27 \%$ of males actually preferred this source; many indicated that they would prefer to obtain information on relationships from their mothers ( $29 \%$ of females and $15 \%$ of males).

\begin{tabular}{|c|c|c|c|c|}
\hline \multicolumn{5}{|c|}{$\begin{array}{l}\text { Table 1: } \\
\text { How do adolescents obtain SRH information? }\end{array}$} \\
\hline \multirow[b]{2}{*}{$\begin{array}{l}\text { Topic \& } \\
\text { Source }\end{array}$} & \multicolumn{2}{|l|}{ Male } & \multicolumn{2}{|l|}{ Female } \\
\hline & $\begin{array}{l}\begin{array}{l}\text { Current } \\
\text { source } \\
(\%)\end{array} \\
(\mathrm{N}=547)\end{array}$ & $\begin{array}{l}\text { Preferred } \\
\text { source } \\
(\%) \\
(\mathrm{N}=547)\end{array}$ & $\begin{array}{l}\begin{array}{l}\text { Current } \\
\text { source } \\
(\%) \\
(\mathrm{N}=756)\end{array}\end{array}$ & $\begin{array}{l}\text { Preferred } \\
\text { source } \\
(\%) \\
(\mathrm{N}=756)\end{array}$ \\
\hline \multicolumn{5}{|l|}{ Puberty } \\
\hline School teacher & 79.0 & 37.1 & 63.6 & 27.8 \\
\hline Mother & 6.6 & 18.3 & 15.3 & 35.2 \\
\hline Father & 0.2 & 6.0 & 0.3 & 0.4 \\
\hline *Others & 14.3 & 38.6 & 21.3 & 36.8 \\
\hline \multicolumn{5}{|l|}{ Reproduction } \\
\hline School teacher & 74.0 & 39.5 & 64.6 & 33.1 \\
\hline Mother & 3.7 & 13.7 & 11.6 & 28.6 \\
\hline Father & 0.9 & 4.9 & 0.1 & 0.7 \\
\hline${ }^{*}$ Others & 21.4 & 41.9 & 23.7 & 38.6 \\
\hline \multicolumn{5}{|l|}{ Relationships } \\
\hline School teacher & 32.2 & 21.0 & 23.7 & 15.3 \\
\hline Mother & 4.6 & 14.8 & 10.2 & 29.2 \\
\hline Father & 0.9 & 7.1 & 0.1 & 0.9 \\
\hline${ }^{*}$ Others & 62.5 & 57.1 & 66.1 & 54.6 \\
\hline
\end{tabular}

\section{Parent-adolescent discussions of premarital sex}

Parents who talked with their adolescents about sex felt that the following issues are important to discuss:

- Teenage pregnancy (31\%)

- Sex education ((abortion, contraception, abstinence until marriage) $(28 \%))$

- STI/HIV AIDS (14\%)

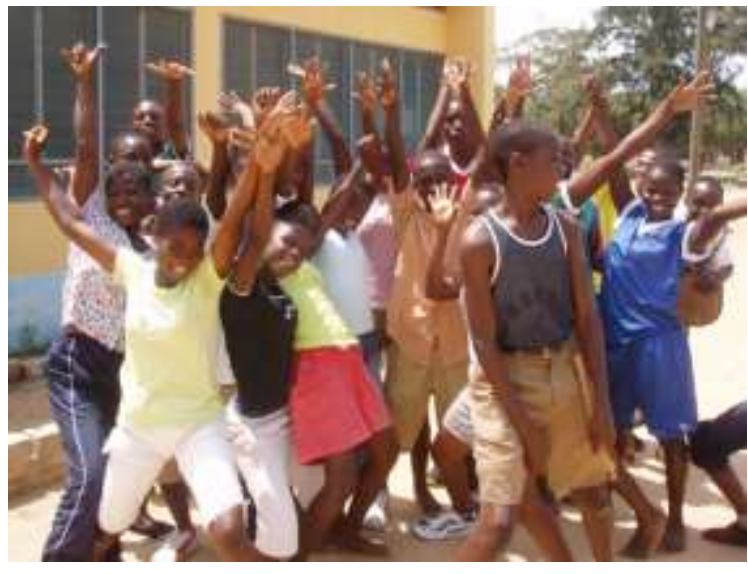

Photo credit: Pen International

- Boy/girl relationships (4\%)

- Alcoholism/smoking (3\%)

- Personal hygiene $(11 \%)$

About three out of five parents (61\%) indicated they had ever discussed sexuality issues with their adolescents. A majority (87\%) of those who had had these discussions indicated they were comfortable and not shy in discussing this subject.

Interestingly, when adolescents were asked whether they had discussed sexuality issues with their parents, their responses differed greatly from their parents'. A majority (89\%) of adolescents indicated that they had never discussed sex related issues with their fathers, $2 \%$ said they often had those discussions and $8 \%$ said they occasionally did. Roughly $69 \%$ of adolescents also indicated they had never had such discussions with their mothers, $9 \%$ often had such discussions, and $22 \%$ occasionally discussed this with their mothers.

There is therefore a mismatch between the proportion of parents who feel that they discussed sexuality with their adolescents and the number of adolescents who agree that these discussions took place. It is possible that what parents consider as communicating on sexuality does not meet the needs of the adolescents, or that parents are ineffectively opening these discussions and the adolescents are unaware of their efforts.

Parents and guardians expressed that they themselves require more information in order to have meaningful discussions on sexuality. Close to $66 \%$ needed more information on family planning, contraceptive use, and STIs and HIVIAIDS; $5 \%$ needed information on abortion; $8 \%$ needed information on puberty, rape and peer pressure; and $9 \%$ needed information on marriage. 


\section{CONCLUSION}

This study echoes several other studies by providing evidence that a majority of parents are not opposed to in-school sex education for their children and welcome the idea of empowering themselves (parents) to have productive discussions with their children. Because the majority of adolescents would prefer to receive information on SRH issues at home yet had never had a discussion on sexuality with either their father $(89 \%)$ or mother $(69 \%)$, there is a clear need and opportunity for improving and increasing these discussions. However, because the majority of parents/guardians (61\%) did believe that they discussed sexual matters with the adolescents, there is the additional need to improve parental efficacy at these discussions. Indeed, $66 \%$ said that they themselves needed more information on the subject matter.

A majority of parents were also uninformed about where adolescents could seek SRH services even in their neighborhood, but were willing to allow them to receive services. Indeed, in agency-based interventions intended to reduce adolescent risk-taking sexual behaviors, preventative sex education efforts of most programs still largely exclude parents as agents of change. Therefore, adolescents continue to lack information from parents/guardians who otherwise could have empowered them. These observations suggest the need to better-inform adolescents by better-informing their parents.

\section{REFERENCES}

1. Aggleton P, Warwick. Young People, Sexuality, HIV and AIDS. Amsterdam, Netherlands: Hard wood academic publishers, 2006.

2. Bastien, S., Kajula, L.J., \& Muhwezi, W.W., 2011. A review of studies of parent-child communication about sexuality and HIVIAIDS in sub-Saharan Africa. Reproductive Health, 8(25), pp. 117.

3. Blake SM, Simkin L, Ledsky R, Perkins C, Calabrese JM. Effects of parent-child communications intervention on young adolescents' risk for onset of early intercourse. Fam Plan Perspect 2001;33:5261.

4. Botchway. Parent and adolescent male's communication about sexuality in the context of HIVIAIDS. MPhil thesis (Unpub), University of Bergen; 2004.

5. Ghana AIDS Commission. Country AIDS Progress Report Ghana. March 2014.

6. Ghana Statistical Service (GSS), Ghana Health Service (GHS), and ICF Macro. 2009. Ghana Demographic and Health Survey 2008. Accra, Ghana: GSS, GHS, and ICF Macro.

\section{Suggested citation:}

Selina F. Esantsi, Francis Onyango, Gloria J. Quansah Asare, Emmanuel O. Kuffour, Placide Tapsoba, Harriet Birungi And lan Askew. "Are Parents Talking to Adolescents about Sexuality? Evidence from Four Slums in Ghana" STEP UP Evidence Brief, August 2015. Accra: Population Council.

\section{DISCUSSION}

- There is a mismatch between the proportion of parents who believe they have discussed sexuality with their adolescents, and the number of adolescents who report they have had these discussions. It is possible that what parents consider as communicating on sexuality does not meet the needs of the adolescents, or that parents are ineffectively opening these discussions and the adolescents are unaware of their efforts.

- The majority of adolescents obtained most of their SRH information from school. However, a high proportion would prefer to receive the information from their parents. It is possible that they prefer the more personalized discussion of SRH related issues that may be had with parents. However, parents are not fulfilling this role adequately to their adolescents' needs.

- Further, there are no structured and effective community-based programs to help parents positively influence their children's sexual behavior.

- The limited-quality communication among parents and adolescents is attributable to parental inexperience in having these discussions and limited knowledge of relevant sexual topics. The sensitive nature of the topics adds to these challenges in communication.

- There is therefore a need to better-educate parents and guardians about both adolescent sexual and reproductive health, as well as provide guidance on how they can effectively have these conversations 